\title{
Two-dimensional echocardiographic assessment of the severity of mitral regurgitation
}

\author{
(i) Nikola Bulj ${ }^{1,2}$ \\ 'University Hospital "Sestre \\ milosrdnice", Zagreb, Croatia \\ 2University of Zagreb School \\ of Medicine, Zagreb, Croatia
}

KEYWORDS: mitral regurgitation, echocardiography, treatment. CITATION: Cardiol Croat. 2018;13(5-6):187. | https://doi.org/10.15836/ccar2018.187

*ADDRESS FOR CORRESPONDENCE: Nikola Bulj, Klinički bolnički centar Sestre milosrdnice, Vinogradska cesta 29, HR-10000 Zagreb, Croatia. / Phone: 385-91-4060411 / E-mail: nikolabulj@gmail.com

ORCID: Nikola Bulj, https://orcid.org/0000-0002-7859-3374

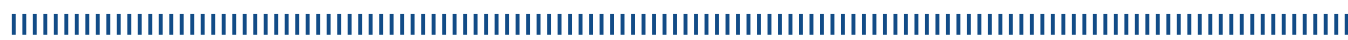

Echocardiography is the primary imaging method for diagnosing mitral regurgitation (MR) and determining the timing and method of treating this valve disorder. Modern techniques for treating MR are setting new challenges requiring echocardiographic assessment to define surgical or interventional treatment strategies, give clear insight in the anatomy and mechanism of MR, as well as the evaluation of pathophysiological and hemodynamic consequences ${ }^{1}$. During echocardiogram, cardiologist has to determine a few important parameters not only to assess the severity of mitral regurgitation, but to describe the mechanism itself using well-known Carpentier's functional classification, which categorizes MR into four types. Furthermore, in order to determine optimal timing for treating patients with $\mathrm{MR}$, echocardiogram must contain information about the consequences of left atrial and left ventricle volume overload, along with the function of right ventricle and pulmonary circulation.

It is important to note that standard transthoracic and Doppler echocardiography provides above mentioned information in the majority of patients. Transesophageal echocardiography should be used in addition to transthoracic echocardiography, primarily to get more details about the anatomy, reparability and functionality of mitral valve ${ }^{2}$. In that regard, it is necessary to define all mitral leaflet segments, commissures and subvalvular apparatus, where three-dimensional transesophageal echocardiography can be of great help.

Advanced echocardiographic techniques, including strain imaging, provide significant information, especially in patients with preserved left ventricular systolic function, but present subclinical myocardial injury, which can affect the decision about earlier surgical treatment.
RECEIVED:

April 21, 2018

ACCEPTED:

May 10, 2018

1. Zoghbi WA, Enriquez-Sarano M, Foster E, Grayburn PA, Kraft CD, Levine RA, et al; American Society of Echocardiography. Recommendations for evaluation of the severity of native valvular regurgitation with two-dimensional and Doppler echocardiography. J Am Soc Echocardiogr. 2003 Jul;16(7):777-802. https://doi.org/10.1016/\$0894-7317(03)00335-3

2. Ray S. The echocardiographic assessment of functional mitral regurgitation. Eur J Echocardiogr. 2010 Dec;11(10):111-17. https://doi.org/10.1093/ejechocard/jeq121 